\title{
Elevated plasma levels of epithelial and endothelial cell markers in COVID-19 survivors with reduced lung diffusing capacity six months after hospital discharge
}

Oriol Sibila ${ }^{1,2,3^{*}+} \oplus$, Lídia Perea ${ }^{2,3 \dagger}{ }^{2}$ Núria Albacar ${ }^{1,2,3}$, Jorge Moisés ${ }^{1,2,3}$, Tamara Cruz ${ }^{2,3}$, Núria Mendoza ${ }^{2,3}$, Belen Solarat 1,2,3, Gemma Lledó2,4 Gerard Espinosa ${ }^{2,4}$, Joan Albert Barberà1,2,3, Joan Ramon Badia1,2,3, Alvar Agustí $1^{1,2,3}$, Jacobo Sellarés ${ }^{1,2,3}$ and Rosa Faner ${ }^{2,3}$

\begin{abstract}
Background: Some COVID-19 survivors present lung function abnormalities during follow-up, particularly reduced carbon monoxide lung diffusing capacity (DLCO). To investigate risk factors and underlying pathophysiology, we compared the clinical characteristics and levels of circulating pulmonary epithelial and endothelial markers in COVID-19 survivors with normal or reduced DLCO 6 months after discharge.

Methods: Prospective, observational study. Clinical characteristics during hospitalization, and spirometry, DLCO and plasma levels of epithelial (surfactant protein (SP) A (SP-A), SP-D, Club cell secretory protein-16 (CC16) and secretory leukocyte protease inhibitor (SLPI)), and endothelial (soluble intercellular adhesion molecule 1 (sICAM-1), soluble E-selectin and Angiopoietin-2) 6 months after hospital discharge were determined in 215 COVID-19 survivors.

Results: DLCO was < 80\% ref. in 125 (58\%) of patients, who were older, more frequently smokers, had hypertension, suffered more severe COVID-19 during hospitalization and refer persistent dyspnoea 6 months after discharge. Multivariate regression analysis showed that age $\geq 60$ years and severity score of the acute episode $\geq 6$ were independent risk factors of reduced DLCO 6 months after discharge. Levels of epithelial (SP-A, SP-D and SLPI) and endothelial (sICAM-1 and angiopoietin-2) markers were higher in patients with reduced DLCO, particularly in those with DLCO $\leq 50 \%$ ref. Circulating SP-A levels were associated with the occurrence of acute respiratory distress syndrome (ARDS), organizing pneumonia and pulmonary embolisms during hospitalization.
\end{abstract}

Conclusions: Reduced DLCO is common in COVID-19 survivors 6 months after hospital discharge, especially in those older than 60 years with very severe acute disease. In these individuals, elevated levels of epithelial and endothelial markers suggest persistent lung damage.

Keywords: Post-COVID, Sequelae, DLCO, Epithelial markers, Endothelial markers

*Correspondence: osibila@clinic.cat

${ }^{\dagger}$ Oriol Sibila and Lídia Perea share the first authorship

1 Pulmonary Service, Respiratory Institute, Hospital Clínic, University of Barcelona, CNillaroel 170, 08036 Barcelona, Spain

Full list of author information is available at the end of the article

\section{Background}

About $20 \%$ of patients infected by SARS-CoV-2 require hospitalization for pneumonia (COVID-19) [1]. The epidemiological, pathophysiology and clinical characteristics of these patients during the acute phase of the disease have been extensively described [2], but potential

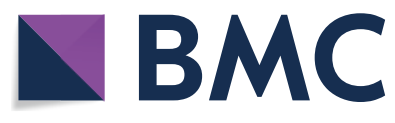

(c) The Author(s) 2022. Open Access This article is licensed under a Creative Commons Attribution 4.0 International License, which permits use, sharing, adaptation, distribution and reproduction in any medium or format, as long as you give appropriate credit to the original author(s) and the source, provide a link to the Creative Commons licence, and indicate if changes were made. The images or other third party material in this article are included in the article's Creative Commons licence, unless indicated otherwise in a credit line to the material. If material is not included in the article's Creative Commons licence and your intended use is not permitted by statutory regulation or exceeds the permitted use, you will need to obtain permission directly from the copyright holder. To view a copy of this licence, visit http://creativecommons.org/licenses/by/4.0/. The Creative Commons Public Domain Dedication waiver (http://creativeco mmons.org/publicdomain/zero/1.0/) applies to the data made available in this article, unless otherwise stated in a credit line to the data. 
long-term pulmonary sequelae, risk factors and underlying mechanisms in survivors remain still unclear. Previous studies showed that COVID-19 survivors may present lung function abnormalities both at hospital discharge [3] and at 3-6 months follow-up [4-10], particularly reduced carbon monoxide lung diffusion capacity (DLCO) which is observed in 20 to $80 \%$ of them. The clinical severity of COVID-19 [4, 5], radiologic extension [5], development of acute respiratory distress syndrome (ARDS) [4, 5] and pulmonary embolism [4, 8] during the acute episode increases the risk of abnormal DLCO during follow-up, but whether this DLCO impairment is temporary [9] or persistent over time [10] is unclear. Likewise, the mechanisms underlying reduced DLCO after hospital discharge are also unknown albeit they may likely include epithelial and/or endothelial dysfunction [11].

Several circulating biomarkers can reflect pulmonary epithelial and endothelial damage [12]. Surfactant proteins (SP), such as SP-A and SP-D, are pulmonary secreted proteins mainly by the alveolar type II epithelial cells (AEC-II) that leak into the bloodstream when the alveolocapillary barrier is damaged [13]. Other epithelial markers such as Club cell secretory protein-16 (CC16), a secretoglobin mainly produced by Club epithelial cells, and secretory leukocyte protease inhibitor (SLPI), one of the major protease inhibitors at mucosal surfaces, are found at high concentrations in plasma when pulmonary injury occurs $[14,15]$. On the other hand, other circulating biomarkers, like soluble sE-selectin, Angiopoietin-2 and intercellular adhesion molecule 1 (sICAM-1), reflect activated or damaged endothelium [16]. In fact, previous reports showed that during the acute phase of COVID19, sE-selectin, Angiopoietin-2 and sICAM-1 are associated with disease severity [17-19]. In survivors of COVID-19, these epithelial markers have not been investigated so far and their potential role in relation to longterm pulmonary sequelae is unknown.

We hypothesize that severe COVID-19 damage epithelial and/or endothelial lung cells and that such damage persists in patients with reduced DLCO after hospital discharge. To test this hypothesis, we compared the clinical characteristics, risk factors and circulating levels of epithelial and endothelial markers 6 months after hospital discharge in survivors of COVID-19 with normal or reduced DLCO.

\section{Methods}

\section{Study design, participants and ethics}

This prospective, observational study included 215 adults who were hospitalized in our institution between May and November 2020 because of PCR-confirmed COVID19 pneumonia and studied at 6 months after hospital discharge. Figure 1 presents the consort diagram of the study. STROBE guidelines were used to ensure the reporting of this observational study [20]. The study protocol was approved by the Ethical Review Board of our hospital (HCB/2020/0422), and all patients signed their informed consent.

\section{Measurements}

Demographic, clinical and biological characteristics were recorded on hospital admission and at 6 months after discharge. During admission, patients were treated according to international recommendations [21, 22]. The severity of the acute disease was determined according to the seven-category severity scale recommended by WHO [21]: score 3: admitted to the hospital but not requiring supplemental oxygen; score 4: requiring oxygen by mask or nasal prongs; score 5 : requiring non-invasive ventilation or high-flow oxygen; score 6: requiring intubation or mechanical ventilation; and score 7: requiring ventilation plus additional organ support-pressors, renal replacement therapy (RRT), extracorporeal membrane oxygenation (ECMO). ARDS was defined by the Berlin criteria [23]. Organizing pneumonia was defined as the presence of different degrees of bilateral ground glass opacities with peripheral, linear and perilobular consolidations, some of them with reverse halo appearance, associated with bronchial dilatation and architectural distortion [24].

All patients followed the current Spanish Society of Pulmonology and Thoracic Surgery (SEPAR) consensus for post-COVID-19 clinical follow-up [25]. In all patients, spirometry and DLCO were measured (Medisoft, Sorinnes, Belgium) 6 months after discharge following international recommendations [26, 27] adapted to the current pandemic situation [28, 29]. Reference values were those of a Mediterranean population [30].

Blood was collected in EDTA tubes by peripheral venepuncture 6 months after discharge and was then

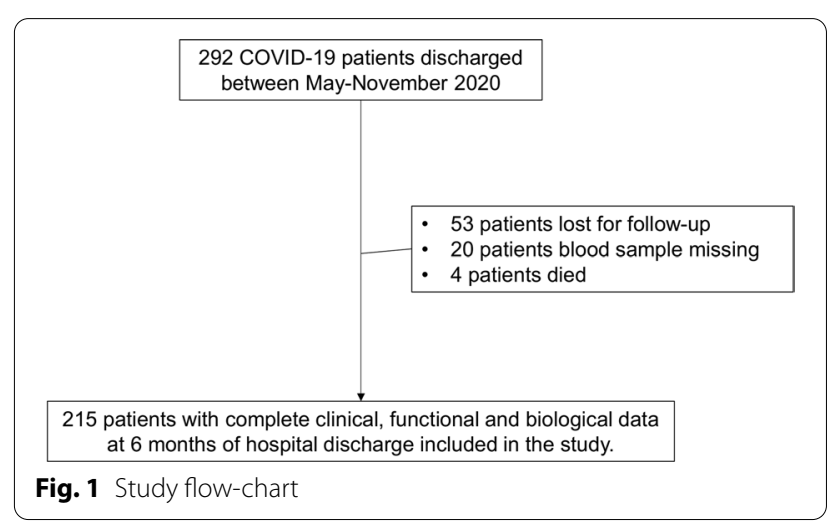


centrifuged at $600 \mathrm{xg} 10 \mathrm{~min} 4^{\circ} \mathrm{C}$ to obtain the plasma which was stored at $-80^{\circ} \mathrm{C}$ until analysis. Plasma CC16, SP-D (Cloud-Clone Corp, TX, USA), SP-A (Novus Biologicals, CO, USA), SLPI, Angiopoietin-2, sICAM-1 (R\&D Systems, Minneapolis, MN, USA) and sE-selectin (RayBiotech, Peachtree Corners, GA) levels were measured by validated commercially available ELISA kits following manufacturer instructions. Plasma samples were diluted 1/10 for CC16, SP-D, SP-A and Angiopoietin-2, $1 / 80$ for SLPI, $1 / 25$ for sE-selectin and $1 / 20$ for sICAM1. The limits of detection were $0.156 \mathrm{ng} / \mathrm{ml}$ for CC16, $0.625 \mathrm{ng} / \mathrm{ml}$ for SP-D, $15.625 \mathrm{pg} / \mathrm{ml}$ for SP-A, $62.5 \mathrm{pg} /$ $\mathrm{ml}$ for SLPI, $24.7 \mathrm{pg} / \mathrm{ml}$ for $\mathrm{sE}$-selectin, $1.6 \mathrm{ng} / \mathrm{ml}$ for sICAM-1 and $46.9 \mathrm{pg} / \mathrm{ml}$ for Angiopoietin-2.

\section{Statistical analysis}

Participants were categorized according their DLCO values at 6 months after discharge as normal ( $\geq 80 \%$ ref.) or low $(<80 \%$ ref.); the latter were further subdivided as moderate $(80-50 \%$ ref.) or severe $(<50 \%$ ref.). Results are presented as $\mathrm{n}$, frequency, mean \pm standard deviation (SD), median [interquartile range -IQR]. Groups were compared using ANOVA, Student $t$-test, $x^{2}$. Fisher exact test, Kruskal-Wallis or Mann-Whitney tests, as appropriate according to the normal data distribution Multiple comparisons between groups were analyzed by the Dunn's test. Bivariate correlations were analysed using the Spearman rank test. Multivariable adjusted logistic regression models were used to investigate risk factors of low DLCO (<80\% ref.), with age, hypertension, smoking status (never, current, former) and WHO acute disease severity score as independent variables. A $\mathrm{p}$ value $<0.05$ was considered significant. Analyses were performed using R version 3.6.1, SPSS version 20 (IBM Inc, Armonk, NY) or GraphPad Prism 7 (GraphPad Software, Inc, La Jolla, Calif).

\section{Results}

\section{Cohort characteristics}

Mean age was $61.4 \pm 11.8$ years, and $66 \%$ of patients were male. The most frequent comorbid condition prior to hospitalization was arterial hypertension (40\%). Most frequent symptoms on admission were fever $(73 \%)$, cough (59\%) and dyspnoea (46\%). $44 \%$ of patients were admitted to the ICU, and $22 \%$ required mechanical ventilation. ARDS was observed in $35 \%$ of patients, while organizing pneumonia and pulmonary embolism occurred in 50\% and $7 \%$ respectively during hospital admission. Length of hospital stay was $21.3 \pm 18.6$ days.

At 6 months follow-up, 52\% of patients remained symptomatic, predominantly with dyspnoea (26\%) and fatigue $(18 \%)$. On average, spirometry was normal (Forced expiratory volume in $1^{\text {st }}$ second $\left(\mathrm{FEV}_{1}\right) 94.7[83.5-105.8] \%$ ref, Forced Vital Capacity (FVC) 91.9 [81-103] \% ref., and $\mathrm{FEV}_{1} / \mathrm{FVC} 79.1$ [73.9-83]). Mean DLCO was 76.6 [64.7-91] \% ref. Collectively, 136 (63.7\%) patients had one or more abnormal lung function value. Specifically, 43 patients (20\%) had abnormal $\mathrm{FEV}_{1}, 47$ patients (21.9\%) had abnormal FVC and 125 patients (58.1\%) had abnormal DLCO values (\% ref) (Fig. 2). Among patients with abnormal DLCO, 90 (42\%) had a moderate reduction $(50-80 \%$ ref.) and $35(16 \%)$ a severe one ( $\leq 50 \%$ ref.).

\section{Comparison of patients with normal vs. reduced DLCO 6 months after hospital discharge}

Table 1 shows that patients with reduced DLCO 6 months after hospital discharge were older, more frequently smokers and suffered more arterial hypertension before admission for the acute COVID-19 episode. During hospital admission they had higher levels of C-reactive protein, lactate dehydrogenase $(\mathrm{LDH})$ and circulating leukocytes, suffered more severe disease and required mechanical ventilation more often. Their length of ICU and hospital stay was longer. Six months after hospital discharge, they showed persistent dyspnoea and cough more often, and their mean levels of LDH and circulating leukocytes remained higher. Interestingly, 35 patients (58\%) from score 3 and 4 severity disease had reduced DLCO 6 months after hospital discharge without suffering from respiratory diseases nor smoking.

Table 2 presents the results of univariate and multivariate analyses of risk of abnormal DLCO at 6 months follow-up. Multivariate analysis showed that age $\geq 60$ years (OR 2.92 [95CI 1.64-5.21], $\mathrm{p}<0.001$ ) and WHO severity score 6 (OR 3.03 [95CI 1.14-8.10], $\mathrm{p}=0.02$ ) were independent predictors of reduced DLCO after hospital discharge.

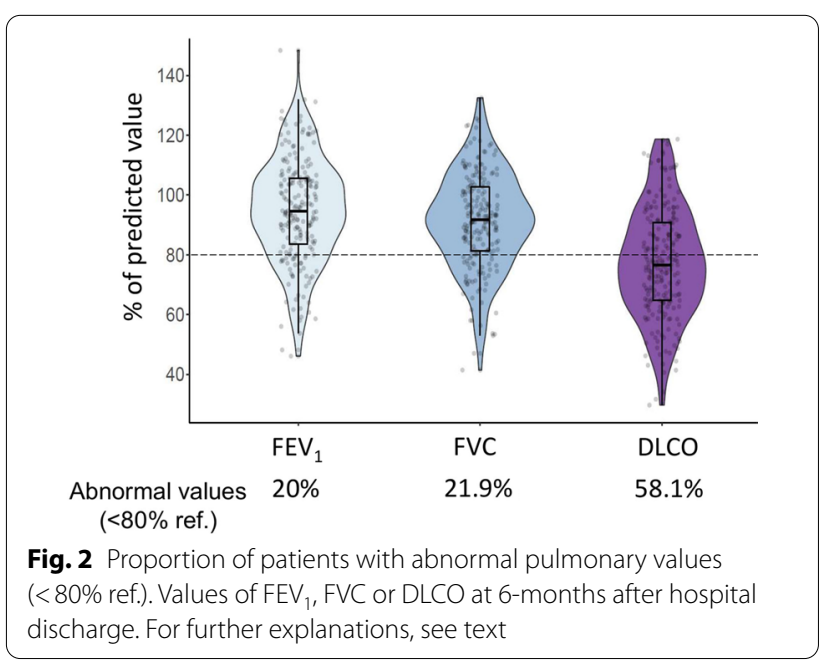


Table 1 Comparison of COVID-19 patients with normal or abnormal DLCO values 6 months after hospital discharge

\begin{tabular}{|c|c|c|c|}
\hline & $\begin{array}{l}\text { DLCO } \geq 80 \% \text { ref } \\
N=90(41.9 \%)\end{array}$ & $\mathrm{DLCO}<80 \%$ ref $\mathrm{N}=125(58.1 \%)$ & $p$-value \\
\hline \multicolumn{4}{|l|}{ Demographics and clinical characteristics } \\
\hline Male (n, \%) & $59(65.6)$ & $71(56.8)$ & 0.2 \\
\hline Age (years) & $56.9 \pm 12.7$ & $65.3 \pm 10.4$ & $<0.0001$ \\
\hline Smoking (n, \%) & & & 0.02 \\
\hline Never & $71(78.9)$ & $77(61.6)$ & \\
\hline Current & $1(1.1)$ & $6(4.8)$ & \\
\hline Former & $18(20)$ & $42(33.6)$ & \\
\hline \multicolumn{4}{|l|}{ Comorbidities, (n, \%) } \\
\hline Hypertension & $26(28.9)$ & $59(47.2)$ & 0.007 \\
\hline Diabetes & $5(5.6)$ & $15(12)$ & 0.2 \\
\hline Cardiovascular disease & $8(8.9)$ & $22(17.6)$ & 0.07 \\
\hline Asthma & $5(5.6)$ & $8(6.4)$ & 1 \\
\hline COPD & $2(2.2)$ & $7(5.6)$ & 0.3 \\
\hline Hepatic disease & $5(5.6)$ & $5(4)$ & 0.7 \\
\hline Solid neoplasm & $3(3.3)$ & $5(4)$ & 1.0 \\
\hline \multicolumn{4}{|l|}{ Acute COVID-19 (in hospital) } \\
\hline \multicolumn{4}{|l|}{ Symptoms, (n, \%) } \\
\hline Any one of the following symptoms & $75(83.3)$ & $98(78.4)$ & 0.4 \\
\hline Fever & $70(77.8)$ & $87(69.6)$ & 0.2 \\
\hline Cough & $57(63.3)$ & $70(56)$ & 0.3 \\
\hline Dyspnoea & $38(42.2)$ & $60(48)$ & 0.4 \\
\hline Joint Pain & $23(25.6)$ & $24(19.2)$ & 0.3 \\
\hline Diarrhoea & $21(23.3)$ & $20(16)$ & 0.2 \\
\hline Sputum production & $10(11.1)$ & $16(12.8)$ & 0.7 \\
\hline Headache & $13(14.4)$ & $5(4)$ & 0.01 \\
\hline Chest Pain & $11(12.2)$ & $7(5.6)$ & 0.1 \\
\hline \multicolumn{4}{|l|}{ Biomarkers } \\
\hline CRP (mg/dL) & $6.7[3.6-14.5]$ & $10.4[6.4-20]$ & 0.003 \\
\hline D-dimer (ng/mL) & $1015 \pm 1470$ & $1493 \pm 2152$ & 0.1 \\
\hline Ferritin (ng/mL) & $892.7 \pm 862.1$ & $1026.8 \pm 987.7$ & 0.5 \\
\hline $\mathrm{LDH}(\mathrm{U} / \mathrm{L})$ & $303[240-378]$ & $362[287-500]$ & 0.002 \\
\hline Creatinine (mg/dL) & $0.8 \pm 0.2$ & $1 \pm 0.6$ & 0.06 \\
\hline Platelets $\left(10^{9} / \mathrm{L}\right)$ & $205.9 \pm 87.5$ & $242.8 \pm 270.4$ & 0.3 \\
\hline Leukocytes $\left(10^{9} / \mathrm{L}\right)$ & $5.8 \pm 2.3$ & $6.9 \pm 3.9$ & 0.04 \\
\hline Lymphocytes $\left(10^{9} / \mathrm{L}\right)$ & $0.9 \pm 0.4$ & $0.8 \pm 0.5$ & 0.6 \\
\hline \multicolumn{4}{|l|}{ Severity of disease (WHO), $(\mathrm{n}, \%)$} \\
\hline Score 3 & $26(28.9)$ & $23(18.4)$ & 0.04 \\
\hline Score 4 & $29(32.2)$ & 37 (29.6) & \\
\hline Score 5 & $24(26.7)$ & $29(23.2)$ & \\
\hline Score 6 & $6(6.7)$ & $21(16.8)$ & \\
\hline Score 7 & $5(5.6)$ & $15(12)$ & \\
\hline \multicolumn{4}{|l|}{ Hospitalization (n, \%) } \\
\hline ICU admission & $34(37.8)$ & $61(48.8)$ & 0.1 \\
\hline MV & $11(12.2)$ & $36(28.8)$ & 0.004 \\
\hline NIMV & $6(6.7)$ & $15(12)$ & 0.2 \\
\hline ARDS & $22(24.4)$ & $53(42.4)$ & 0.006 \\
\hline Organizing pneumonia & $39(43.3)$ & $68(54.4)$ & 0.1 \\
\hline Pulmonary embolism & $3(3.3)$ & $12(9.6)$ & 0.1 \\
\hline Length of hospital stay & 13 & 19 & $<0.0001$ \\
\hline
\end{tabular}


Table 1 (continued)

\begin{tabular}{|c|c|c|c|}
\hline & $\begin{array}{l}\mathrm{DLCO} \geq 80 \% \text { ref } \\
\mathrm{N}=90(41.9 \%)\end{array}$ & DLCO $<80 \%$ ref $N=125(58.1 \%)$ & $p$-value \\
\hline Length of ICU stay & 7 & 18 & 0.002 \\
\hline \multicolumn{4}{|l|}{6 months after hospital discharge } \\
\hline \multicolumn{4}{|l|}{ Symptoms, (n, \%) } \\
\hline Any one of the following symptoms & $42(46.7)$ & $69(55.2)$ & 0.2 \\
\hline Dyspnoea & $14(15.6)$ & $42(33.6)$ & 0.003 \\
\hline Fatigue & $19(21.1)$ & $31(24.8)$ & 0.6 \\
\hline Cough & $7(7.8)$ & $23(18.4)$ & 0.03 \\
\hline Joint Pain & $6(6.7)$ & $15(12)$ & 0.2 \\
\hline Diarrhoea & $1(1.1)$ & $3(2.4)$ & 0.6 \\
\hline Sputum production & $5(5.6)$ & $12(9.6)$ & 0.3 \\
\hline Headache & $8(8.9)$ & $8(6.4)$ & 0.6 \\
\hline Chest pain & $10(1.1)$ & $9(7.2)$ & 0.3 \\
\hline \multicolumn{4}{|l|}{ Biomarkers } \\
\hline CRP (mg/dL) & $0.5 \pm 0.2$ & $0.5 \pm 0.5$ & 0.4 \\
\hline D-dimer (ng/mL) & $360 \pm 291$ & $510 \pm 998$ & 0.4 \\
\hline Ferritin (ng/mL) & $127 \pm 102$ & $113 \pm 108$ & 0.7 \\
\hline $\mathrm{LDH}(\mathrm{U} / \mathrm{L})$ & 172 [155-190] & 192 [172-209] & 0.001 \\
\hline Creatinine (mg/dL) & $0.9 \pm 0.2$ & $1.1 \pm 1.1$ & 0.2 \\
\hline Platelets $\left(10^{9} / \mathrm{L}\right)$ & $227.9 \pm 63$ & $233.9 \pm 74.5$ & 0.7 \\
\hline Leukocytes $\left(10^{9} / \mathrm{L}\right)$ & $6.2 \pm 1.3$ & $7.2 \pm 2.6$ & 0.02 \\
\hline Lymphocytes $\left(10^{9} / L\right)$ & $1.9 \pm 0.6$ & $2.2 \pm 0.7$ & 0.08 \\
\hline
\end{tabular}

Data is presented as mean \pm standard deviation or median [interquartile range]. Significantly different variables $(p<0.05)$ are highlighted using bold text COPD chronic obstructive pulmonary disease, $I C U$ intensive care unit, $L D H$ lactate dehydrogenase, $C R P$ protein $C$ reactive, $M V$ mechanical ventilation, $N I V$ non-invasive mechanical ventilation

Table 2 Univariate and multivariate analysis for risk of abnormal DLCO at 6-months

\begin{tabular}{|c|c|c|c|c|c|c|}
\hline \multirow[b]{2}{*}{ Variables } & \multicolumn{3}{|c|}{ Univariate analysis } & \multicolumn{3}{|c|}{ Multivariate analysis } \\
\hline & OR & $\mathrm{Cl} 95 \%$ & p-value & OR & $\mathrm{Cl} 95 \%$ & $p$-value \\
\hline Age $\geq 60$ years & 2.38 & $1.30-4.35$ & 0.005 & 2.92 & $1.64-5.21$ & $<0.001$ \\
\hline Hypertension & 1.63 & $0.87-3.06$ & 0.13 & & & \\
\hline Former and current smokers & 1.88 & $0.97-3.66$ & 0.06 & & & \\
\hline Disease severity score 4 & 1.43 & $0.66-3.14$ & 0.37 & & & \\
\hline Disease severity score 5 & 1.48 & $0.65-3.37$ & 0.36 & & & \\
\hline Disease severity score 6 & 4.00 & $1.31-12.16$ & 0.015 & 3.03 & $1.14-8.10$ & 0.027 \\
\hline Disease severity score 7 & 3.70 & $1.10-12.46$ & 0.035 & 2.95 & $0.99-8.77$ & 0.052 \\
\hline
\end{tabular}

Variables that remained significant $(\mathrm{p}<0.05)$ in the multivariate analysis are highlighted in bold text

OR odds ratio, $\mathrm{Cl} 95 \% 95 \%$ confidence interval

\section{Epithelial and endothelial biomarkers}

Patients with reduced DLCO 6 months after discharge had significantly higher circulating levels of both epithelial (SP-A, SP-D, SLPI) and endothelial (sICAM-1 and Angiopoietin-2) markers, particularly in those with severely reduced DLCO ( $<50 \%$ ref.) (Fig. 3). Significant associations also existed between DLCO values and these biomarkers (SP-A, rho $=-0.32, \mathrm{p}<0.001$;
SP-D, rho $=-0.25, \mathrm{p}<0.001$; SLPI, rho $=-0.15, \mathrm{p}=0.03$; sICAM-1, rho $=-0.26, \mathrm{p}<0.001$; and Angiopoietin-2, rho $=-0.15, p=0.03$ ) (see Additional file 1). Once patients that required mechanical ventilation were excluded from the analysis, SP-A $(\mathrm{p}=0.004)$, SP-D $(\mathrm{p}=0.002)$ and sICAM-1 $(\mathrm{p}=0.025)$ still being significantly higher in patients with altered DLCO compared with patients with normal DLCO values. After this 


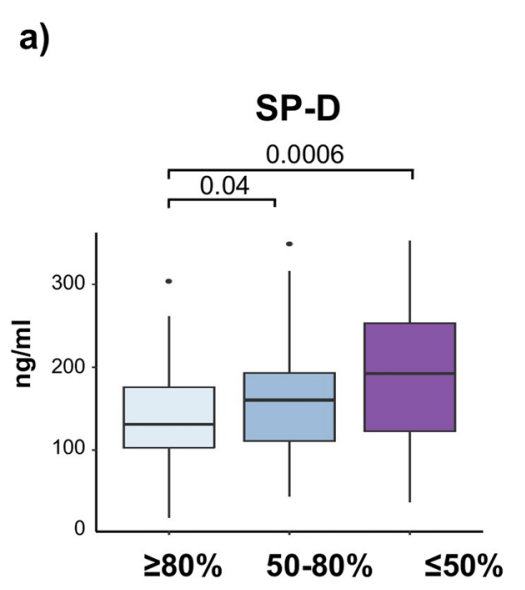

\section{EPITHELIAL MARKERS}

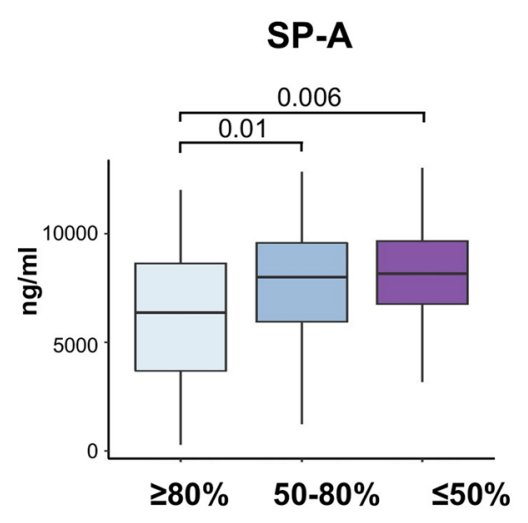

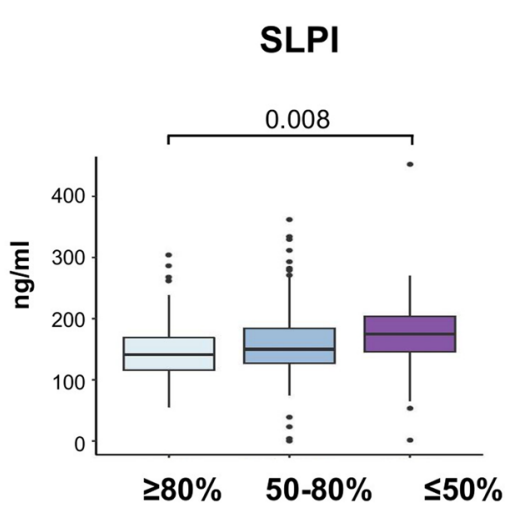

b)

\section{ENDOTHELIAL MARKERS}
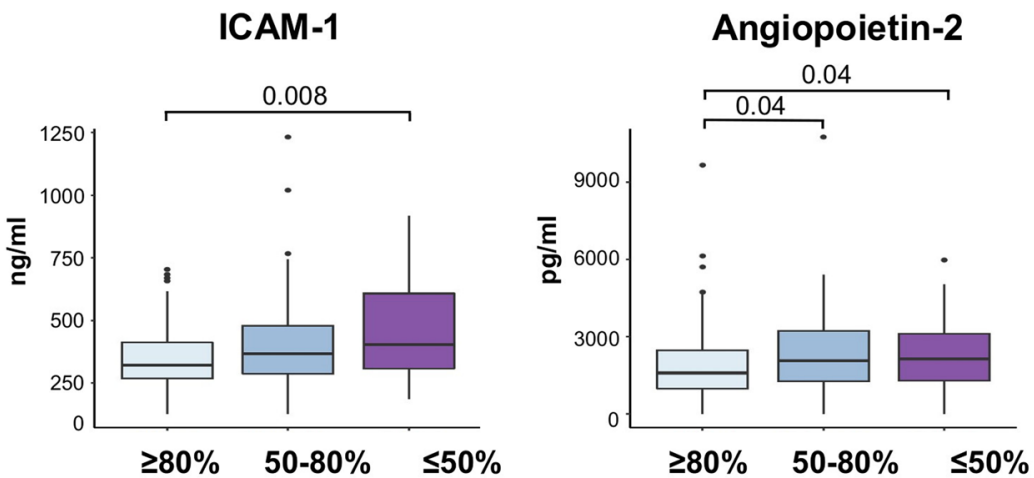

Fig. 3 Association between epithelial and endothelial markers and the grades of DLCO alteration. a Levels of surfactant proteins (SP) A, SP-D and secretory leukocyte protease inhibitor (SLPI) as epithelial markers and $\mathbf{b}$ intercellular adhesion molecule 1 (sICAM-1) and Angiopoietin-2 as endothelial markers significantly increased in patients with the most abnormal DLCO $(\leq 50 \%)$. Kruskal-Wallis tests are applied, and the adjusted $P$-values are obtained by Dunn's test correction

exclusion, significant associations still existing between DLCO values and SP-A (rho $=-0.32, \mathrm{p}<0.001$ ), SP-D (rho $=-0.25, \mathrm{p}=0.001$ ) and sICAM-1 (rho $=-0.24$, $\mathrm{p}=0.002$ ). Also, when patients with comorbidities such as respiratory diseases, hypertension or diabetes were excluded, SP-A, SP-D and SICAM-1 remained significantly higher in this group of patients. When we analyzed the relationship of these markers with blood parameters, we observed weak but significant associations between sICAM-1 levels and LDH (rho=0.3, p=0.001) and D-dimer ( $r h o=0.23, p=0.03$ ) levels. No differences in CC16 [ng/ml, 24 (14.3-35.4) vs 22.5 (14.8-36.4), $\mathrm{p}=0.7$ ] and sE-selectin [ng/ml, $12.7(6.5-25.6)$ vs 12.1 (6.9925.5), $\mathrm{p}=0.8$ ] levels were found among patients with normal and reduced DLCO.

Finally, we explored if the levels of these circulating markers during the follow-up were related to the acute
COVID-19 event. Figure 4 shows that SP-A levels were higher in patients with more severe acute disease (WHO scores 6 and 7) or in those who had suffered ARDS, organizing pneumonia and pulmonary embolism during hospitalization. Additionally, patients who suffered ARDS had higher levels of SLPI (ng/ml, 160.6 (138.8-204) vs 143.6 (121.5-175.6), $\mathrm{p}=0.008)$ and patients who develop organizing pneumonia had higher levels of SP-D (ng/ $\mathrm{ml}, 160.7$ (116.6-200.8) vs 147.3 (102-185), $\mathrm{p}=0.048)$. Of note, endothelial biomarkers levels during follow-up were not related with events during hospitalization.

\section{Discussion}

This study shows that, 6 months after discharge, reduced DLCO is common in COVID-19 survivors, that age older than 60 years and mechanical ventilation requirement are significant risk factors, and that these patients present 


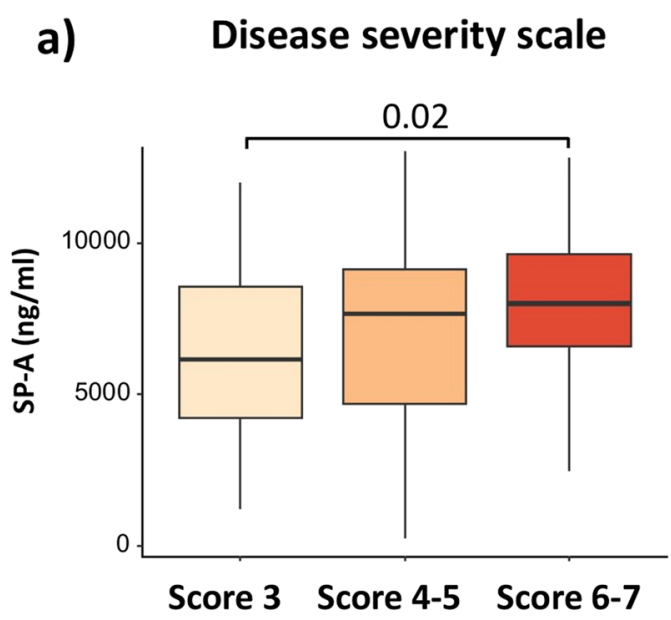

c) Organizing pneumonia

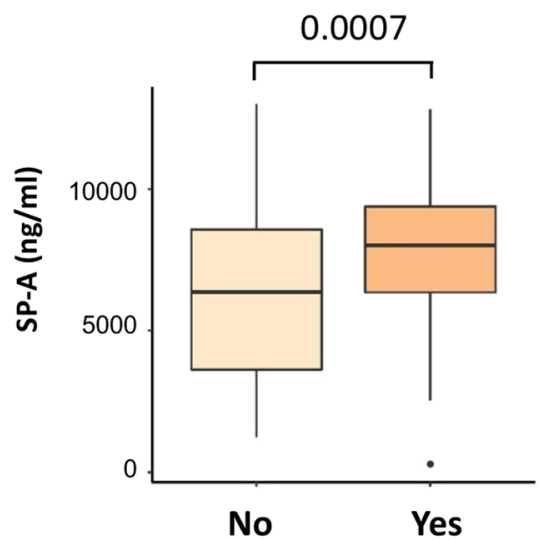

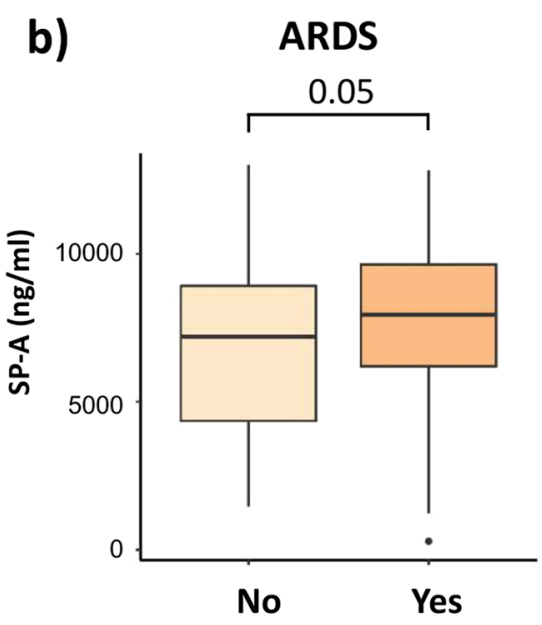

d) Pulmonary embolism

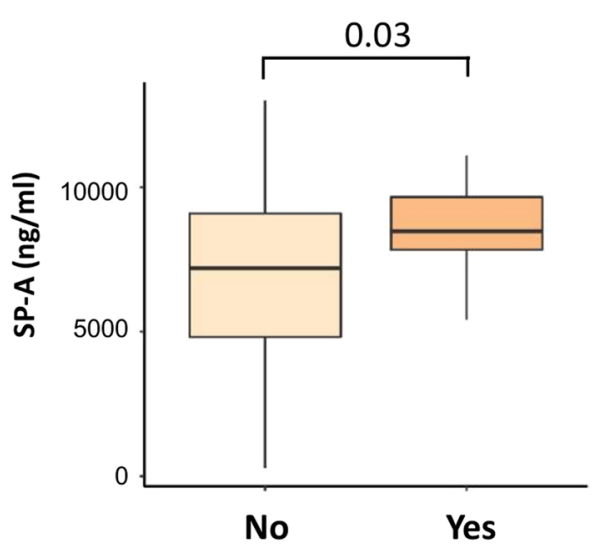

Fig. 4 Association between epithelial markers and clinical severity during hospitalization. Surfactant protein (SP) A levels according to a the severity scale, $\mathbf{b}$ acute distress respiratory syndrome (ARDS), $\mathbf{c}$ the development of organizing pneumonia and $\mathbf{d}$ pulmonary embolism. KruskalWallis test or Mann-Whitney test are applied, as appropriate. The adjusted P-values are obtained by Dunn's test correction

elevated systemic levels of several circulating markers of lung epithelial and endothelial damage. Collectively, these observations suggest that epithelial and endothelial lung damage persist in severe COVID-19 patients for at least 6-months after hospital discharge. These results have a direct relationship with DLCO values, although whether these are permanent or reversible changes, and whether this is cause or consequence of COVID-19, require follow-up of these patients.

\section{Previous studies}

Our clinical and functional findings here are in keeping with previous studies by our group and others evaluating DLCO after hospital discharge in COVID-19 survivors [3-8]. They are also in line with the reduction in DLCO observed in non-COVID-19-related ARDS survivors at 6- and 12-months after hospital discharge $[31,32]$. Although recent studies have suggested cardiopulmonary recovery after COVID-19 [9], our findings indicate that a subgroup of patients ( $\geq 60$ years requiring mechanical ventilation and/or additional organ support during admission because of acute COVID19) still present reduced DLCO 6 months after discharge. The pathophysiological causes for persistent alterations in gas-blood exchange are not fully elucidated yet, but reduced DLCO may suggest interstitial or pulmonary vascular alterations caused by COVID19 [3]. These structural lung changes may damage diffusion membrane, especially in those patients with severe disease. Their future follow-up will help to elucidate if these alterations are permanent or resolve with time. 


\section{Interpretation of novel findings}

It has been recently recommended that clinical observational studies on post-COVID-19 conditions investigate biomarkers after, at least, 6 months post-hospital discharge [33]. To our knowledge, this is the first study to do so. We found that the epithelial markers SP-A, SP-D and SLPI are increased in patients with abnormal DLCO 6 months after hospital discharge, reflecting a persistent epithelial injury. SP-A and SP-D are surfactant-related soluble pattern recognition receptors mainly produced by alveolar-epithelial type II cells (AEC-II) and involved in the lung innate immune response against viral and bacterial pathogens [34]. Some previous studies have reported elevated serum SP-D levels during the acute COVID-19 episode and suggested that this may be protective [3537]. Although Club cells can both secrete CC16 and surfactant proteins, $\mathrm{CC} 16$ levels were not associated with reduced DLCO in COVID-19 patients. These results may suggest that AEC-II cells are one of the key cells involved in the pathophysiology of reduced DLCO in COVID19 survivors. Interestingly, SP-A also participates in the protease and antiprotease activity through the regulation of SLPI [38], suggesting that the elevated SLPI levels observed in patients with reduced DLCO may be induced by the high SP-A concentrations.

Regarding the endothelial markers, although sICAM-1 and Angiopoietin-2 are not specific biomarkers for pulmonary vasculature, we found that their levels were increased in patients with abnormal DLCO 6-months after hospital discharge. Both markers are elevated during the acute phase of SARS-CoV-2 infection in relation to disease severity [17-19]. sE-selectin was found to be increased during the acute phase, especially in COVID19-related ARDS [17], but we did not observe any significant relationship with reduced DLCO at 6-months after hospital discharge. This fact suggests that sE-selectin may have a role only during the initial steps of the pulmonary vasculature damage. Therefore, our findings highlight a persistent endothelial injury in patients with lung sequelae. However, there is a temporal evolution of the endothelial dysfunction markers during the progression of the disease that it should be considered. Viecelli Dalla Sega F. et al.showed that the time course for some endothelial dysfunction markers was different between COVID-19 survivors and non-survivors [39]. Further studies evaluating the levels of these markers during an extended follow-up are needed to know their stability over time.

We also observed, as other works, that patients with mild and moderate COVID-19 can also suffer long-term sequelae [33]. In fact, several of the biomarkers quantified here, including SP-D, SP-A and sICAM-1 still being higher after excluding by mechanical ventilation requirement. Also, these markers still being significantly different when patients with hypertension and/or diabetes are excluded, suggesting that our results are not biased by the comorbidities of the population. In contrast, we observed that SLPI and Angiopoietin-2 did not remain associated with reduced DLCO after mechanical ventilation exclusion, suggesting that they are markers dependent of ventilator-induced lung damage. However, the associations shown in our study may not be causative, and further studies are needed to address this question.

\section{Potential limitations}

Our study has several limitations. First, DLCO measurements were not available before COVID-19, so we cannot discard that the patients studied here might have reduced DLCO before suffering COVID-19. However, this is unlikely because the proportion of patients with previously known respiratory diseases in our cohort was very small. Second, data about additional explorations at 6 -months were not available for the analysis. Third, we did not include a control group in our study, so we do not know if the levels determined in the patients studied here are normal or not. Yet, it is unclear what type of control individuals should be studied here, healthy ones or survivors of other acute infective episodes. Finally, these biomarkers were not measured during the admission nor at hospital discharge but 6 months later. Future studies will have to validate them as potential prognostic markers of lung sequelae after discharge.

\section{Conclusions}

This study shows that reduced DLCO is frequent in COVID-19 patients 6 months after hospital discharge, particularly in those older than 60 years who required mechanical ventilation during admission. We also showed that several circulating epithelial and endothelial pulmonary markers are increased in patients with reduced DLCO. All in all, our results indicate that the pulmonary injury induced by SARS-CoV-2 can leave pulmonary damage six months after hospital discharge. Future studies will have to investigate if this damage is transient or permanent.

\section{Abbreviations}

AEC-II: Alveolar type II epithelial cells; ARDS: Acute respiratory distress syndrome; CC16: Club cell secretory protein-16; CI 95\%: 95\% Confidence interval; COPD: Chronic obstructive pulmonary disease; CRP: Protein C reactive; DLCO: Carbon monoxide lung diffusion capacity; EDTA: Ethylenediaminetetraacetic acid; FEV 1 : Forced expiratory volume in 1st second; FVC: Forced vital capacity; SICAM-1: Soluble intercellular adhesion molecule 1; ICU: Intensive care unit; IQR: Interquartile range; RRT: Renal replacement therapy; ECMO: Extracorporeal membrane oxygenation; LDH: Lactate dehydrogenase; MV: Mechanical ventilation; NIV: Non-invasive mechanical ventilation; OR: Odds ratio; SD: Standard deviation; SLPI: Secretory leukocyte protease inhibitor; SP-A: Surfactant protein A; SP-D: Surfactant protein D. 


\section{Supplementary Information}

The online version contains supplementary material available at https://doi. org/10.1186/s12931-022-01955-5.

Additional file 1: Fig. S1. Additional correlations for DLCO values. Graphs representing the Spearman's rank correlations between DLCO values and epithelial and endothelial biomarkers measured in COVID-19 survivors at 6-months after hospital discharge

\section{Acknowledgements}

Authors thank all participants in the study for the willingness to contribute to medical research, and all field workers for their dedication and quality of their daily work. We are indebted to the HCB-IDIBAPS Biobank for the biological human samples and data procurement and to the Fundació Glòria Soler for its support to the COVIDBANK collection.

\section{Authors' contributions}

OS: Study design, obtained study funding, data analysis, data interpretation and statistical analysis including writing of the final manuscript. LP: Study design, sample processing, performance of experimental work, data collection and statistical analysis including writing of the final manuscript. TC, NM: Sample processing, performance of experimental work and data interpretation. $N A, B S, J M, G L L, G E$, JAB, JRB: Patient recruitment, sample collection, clinical data and data analysis. AA and JS: Study design, data interpretation and writing of the final manuscript. RF: Study design, data analysis, data interpretation and writing of the final manuscript. All authors reviewed, read and approved the final manuscript.

\section{Funding}

This work has been financed by ad hoc patronage funds for research on COVID-19, from donations from citizens and organizations to the Hospital Clinic de Barcelona-Fundació Clinic per a la recerca Biomedica, "bizum solidario" by Fundación BBVA and research grants from Menarini, Sociedad Española de Neumología y Cirugía Torácica (SEPAR) and Agencia de Gestio d'Ajuts Universitaris i de Recerca (AGAUR, PANDEMIES 2020). RF is Miguel Servet Fellow. TC is a Sara Borrell Fellow.

\section{Availability of data and materials}

The datasets used and/or analysed during the current study are available from the corresponding author on reasonable request.

\section{Declarations}

\section{Ethics approval and consent to participate}

The study protocol was approved by the Ethical Review Board of our hospital (HCB/2020/0422), and all patients signed their informed consent.

\section{Consent for publication}

Not applicable.

\section{Competing interests}

The authors declare that they have no competing interests.

\section{Author details}

'Pulmonary Service, Respiratory Institute, Hospital Clínic, University of Barcelona, CNillaroel 170, 08036 Barcelona, Spain. ${ }^{2}$ Institut d'Investigacions Biomèdiques August Pi i Sunyer (IDIBAPS), C/Roselló 149, 08036 Barcelona, Spain. ${ }^{3}$ Centro de Investigación Biomédica en Red de Enfermedades Respiratorias (CIBER), Barcelona, Spain. ${ }^{4}$ Autoimmune Diseases Department, IDIBAPS, University of Barcelona, Hospital Clínic, Barcelona, Spain.

Received: 12 November 2021 Accepted: 10 February 2022

Published online: 21 February 2022

\section{References}

1. Huang C, Wang Y, Li X, Ren L, Zhao J, Hu Y, et al. Clinical features of patients infected with 2019 novel coronavirus in Wuhan, China. Lancet. 2020;395(10223):497-506.

2. Osuchowski MF, Winkler MS, Skirecki T, Cajander S, Shankar-Hari M, Lachmann G, et al. The COVID-19 puzzle: deciphering pathophysiology and phenotypes of a new disease entity. Lancet Respir Med. 2021;9(6):622-42.

3. Mo X, Jian W, Su Z, Chen M, Peng H, Peng P, et al. Abnormal pulmonary function in COVID-19 patients at time of hospital discharge. Eur Respir J. 2020;55(6):2001217

4. Sibila O, Albacar N, Perea L, Faner R, Torralba Y, Hernandez-Gonzalez F, et al. Lung function sequelae in COVID-19 patients 3 months after hospital discharge. Arch Bronconeumol. 2021;57:59-61.

5. Qin W, Chen S, Zhang Y, Dong F, Zhang Z, Hu B, et al. Diffusion capacity abnormalities for carbon monoxide in patients with COVID-19 at threemonth follow-up. Eur Respir J. 2021:58: 2003677.

6. González J, Benítez ID, Carmona P, Santisteve S, Monge A, MoncusíMoix $A$, et al. Pulmonary function and radiological features in survivors of critical COVID-19: a 3-month prospective cohort. Chest. 2021;S0012-3692(21):00464-5.

7. Guler SA, Ebner L, Beigelman C, Bridevaux P-O, Brutsche M, Clarenbach $C$, et al. Pulmonary function and radiological features four months after COVID-19: first results from the national prospective observational Swiss COVID-19 lung study. Eur Respir J. 2021;57(4):2003690.

8. Méndez R, Latorre A, González-Jiménez P, Feced L, Bouzas L, Yépez K, et al Reduced diffusion capacity in COVID-19 survivors. Ann Am Thorac Soc. 2021:18(7):1253-5.

9. Sonnweber T, Sahanic S, Pizzini A, Luger A, Schwabl C, Sonnweber B, et al. Cardiopulmonary recovery after COVID-19: an observational prospective multicentre trial. Eur Respir J. 2021;57(4):2003481.

10. Huang C, Huang L, Wang Y, Li X, Ren L, Gu X, et al. 6-month consequences of COVID-19 in patients discharged from hospital: a cohort study. Lancet. 2021;397(10270):220-32.

11. Hughes JMB, Pride NB. Examination of the carbon monoxide diffusing capacity (DLCO) in relation to its KCO and VA components. Am J Respir Crit Care Med. 2012;186(2):132-9.

12. Bersten AD, Hunt T, Nicholas TE, Doyle IR. Elevated plasma surfactant protein-B predicts development of acute respiratory distress syndrome in patients with acute respiratory failure. Am J Respir Crit Care Med. 2001;164:648-52.

13. Ujma S, Horsnell WGC, Katz AA, Clark HW, Schäfer G. Non-pulmonary immune functions of surfactant proteins A and D. J Innate Immun. 2017;9(1):3-11.

14. Almuntashiri S, Zhu Y, Han Y, Wang X, Somanath PR, Zhang D. Club cell secreted protein CC16: potential applications in prognosis and therapy for pulmonary diseases. J Clin Med. 2020;9(12):4039.

15. Kersul AL, Iglesias A, Ríos Á, Noguera A, Forteza A, Serra E, et al. Molecular mechanisms of inflammation during exacerbations of chronic obstructive pulmonary disease. Arch Bronconeumol. 2011;47(4):176-83.

16. Castro P, Palomo M, Moreno-Castaño AB, Fernández S, Torramadé-Moix

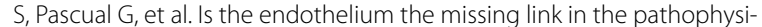
ology and treatment of COVID-19 complications? Cardiovasc Drugs Therapy. 2021. https://doi.org/10.1007/s10557-021-07207-w.

17. Spadaro S, Fogagnolo A, Campo G, Zucchetti O, Verri M, Ottaviani I, et al. Markers of endothelial and epithelial pulmonary injury in mechanically ventilated COVID-19 ICU patients. Crit Care. 2020;25(1):74.

18. Vassiliou AG, Keskinidou C, Jahaj E, Gallos P, Dimopoulou I, Kotanidou A, et al. ICU admission levels of endothelial biomarkers as predictors of mortality in critically III COVID-19 patients. Cells. 2021;10(1):196.

19. Smadja DM, Guerin CL, Chocron R, Yatim N, Boussier J, Gendron N, et al. Angiopoietin-2 as a marker of endothelial activation is a good predictor factor for intensive care unit admission of COVID-19 patients. Angiogenesis. 2020;23(4):611-20.

20. von Elm E, Altman DG, Egger M, Pocock SJ, Gøtzsche PC, Vandenbroucke JP. The strengthening the reporting of observational studies in epidemiology (STROBE) statement: guidelines for reporting observational studies. Lancet. 2007;370(9596):1453-7.

21. World Health Organization WHO R\&D Blueprint novel Coronavirus COVID-19 Therapeutic Trial Synopsis. 2020. https://www.who.int/publi cations/i/item/covid-19-therapeutic-trial-synopsis. 
22. Chalmers JD, Crichton ML, Goeminne PC, Cao B, Humbert M, Shteinberg $\mathrm{M}$, et al. Management of hospitalised adults with coronavirus disease 2019 (COVID-19): a European respiratory society living guideline. Eur Respir J. 2021;57(4):2100048.

23. Ranieri VM, Rubenfeld GD, Thompson BT, Ferguson ND, Caldwell E, Fan E, et al. Acute respiratory distress syndrome: the Berlin definition. JAMA - J Am Med Assoc. 2012;307(23):2526-33.

24. Parekh M, Donuru A, Balasubramanya R, Kapur S. Review of the chest CT differential diagnosis of ground-glass opacities in the COVID era. Radiology. 2020;297(3):E289-302.

25. Sibila O, Molina-Molina M, Valenzuela C, Ríos-Cortés A, Arbillaga-Etxarri A, Torralba García Y, et al. Spanish Society of Pulmonology and Thoracic Surgery (SEPAR) consensus for post-COVID-19 clinical follow-up. Open Respir Arch. 2020;2:278-83.

26. Graham BL, Steenbruggen I, Barjaktarevic IZ, Cooper BG, Hall GL, Hallstrand TS, et al. Standardization of spirometry 2019 update an official American Thoracic Society and European Respiratory Society technical statement. Am J Respir Crit Care Med. 2019;200(8):E70-88.

27. Graham BL, Brusasco V, Burgos F, Cooper BG, Jensen R, Kendrick A, et al. 2017 ERS/ATS standards for single-breath carbon monoxide uptake in the lung. Eur Respir J. 2017;49(1):1600016.

28. Torres-Castro R, Solis-Navarro L, Sitjà-Rabert M, Vilaró J. Functional limitations post-COVID-19: a comprehensive assessment strategy. Arch Bronconeumol. 2020;57(Suppl 1):7-8.

29. Burgos Rincón F, Martínez Llorens J, Cordovilla PR. Impact of the COVID19 pandemic on lung function laboratories: considerations for "today" and the "day after." Arch Bronconeumol. 2020;56(10):611-2.

30. Roca J, Rodriguez-Roisin R, Cobo E, Burgos F, Perez J, Clausen JL. Singlebreath carbon monoxide diffusing capacity prediction equations from a Mediterranean population. Am Rev Respir Dis. 1990;141 (4 I):1026-32.

31. Orme J, Romney JS, Hopkins RO, Pope D, Chan KJ, Thomsen G, et al. Pulmonary function and health-related quality of life in survivors of acute respiratory distress syndrome. Am J Respir Crit Care Med. 2003;167(5):690-4.

32. Herridge MS, Cheung AM, Tansey CM, Matte-Martyn A, Diaz-Granados N, Al-Saidi F, et al. One-year outcomes in survivors of the acute respiratory distress syndrome. N Engl J Med. 2009;348(8):683-93.

33. Soriano JB, Waterer G, Peñalvo JL, Rello J. Nefer, Sinuhe and clinical research assessing post COVID-19 condition. Eur Respir J. 2021;57(4):2004423.

34. Tekos F, Skaperda Z, Goutzourelas N, Phelps DS, Floros J, Kouretas D. The importance of redox status in the frame of lifestyle approaches and the genetics of the lung innate immune molecules, SP-A1 and SP-A2, on differential outcomes of covid-19 infection. Antioxidants. 2020;9(9):1-22.

35. Wu YP, Liu ZH, Wei R, Pan SD, Mao NY, Chen B, et al. Elevated plasma surfactant protein $\mathrm{d}(\mathrm{sp}-\mathrm{d})$ levels and a direct correlation with anti-severe acute respiratory syndrome coronavirus-specific igg antibody in sars patients. Scand J Immunol. 2009;69(6):508-15.

36. Leth-Larsen R, Zhong F, Chow VTK, Holmskov U, Lu J. The SARS coronavirus spike glycoprotein is selectively recognized by lung surfactant protein D and activates macrophages. Immunobiology. 2007;212(3):201-11.

37. Hsieh M-H, Beirag N, Murugaiah V, Chou Y-C, Kuo W-S, Kao H-F, et al. Human surfactant protein $\mathrm{D}$ binds spike protein and acts as an entry inhibitor of SARS-CoV-2 pseudotyped viral particles. Front Immunol. 2021;12:641360.

38. Ramadas RA, Wu L, LeVine AM. Surfactant protein A enhances production of secretory leukoprotease inhibitor and protects it from cleavage by matrix metalloproteinases. J Immunol. 2009;182(3):1560-7.

39. Vieceli Dalla Sega F, Fortini F, Spadaro S, Ronzoni L, Zucchetti O, Manfrini $M$, et al. Time course of endothelial dysfunction markers and mortality in COVID-19 patients: a pilot study. Clin TransI Med. 2021;11(3): e283.

\section{Publisher's Note}

Springer Nature remains neutral with regard to jurisdictional claims in published maps and institutional affiliations.

Ready to submit your research? Choose BMC and benefit from:

- fast, convenient online submission

- thorough peer review by experienced researchers in your field

- rapid publication on acceptance

- support for research data, including large and complex data types

- gold Open Access which fosters wider collaboration and increased citations

- maximum visibility for your research: over $100 \mathrm{M}$ website views per year

At BMC, research is always in progress.

Learn more biomedcentral.com/submissions 